\title{
Rate of Initial Anti-retroviral Treatment Modification and Its Predictors Among Adult Hiv/aids Patients at Pawe General Hospital, Benishangul Gumuz Region, Northwest Ethiopia
}

\section{Tsehay Matso}

Jimma University, Insiue of Healh, Faculty of Health Sciences, School of Pharmacy

\section{Habtamu Jarso}

Jimma University, Insiue of Healh, Faculty of Public Health, Epidemiologaaay department

Girma Mamo ljigu ( $\sim$ girma.mamo2004@gmail.com )

Jimma University, Insiue of Healh, Faculty of Health Sciences, School of Pharmacy

https://orcid.org/0000-0002-1757-8250

\section{Research}

Keywords: Rate, HIV/AIDS, treatment modification, Predictors, Pawe

Posted Date: September 23rd, 2020

DOI: https://doi.org/10.21203/rs.3.rs-78700/v1

License: (c) (1) This work is licensed under a Creative Commons Attribution 4.0 International License.

Read Full License 


\section{Abstract}

Background: Combination antiretroviral therapy (CART) is the cornerstone of managing patients with HIV infection. Once cART is initiated, patients generally remain on medications indefinitely. However, antiretroviral regimens commonly require changes which often involve switches of multiple medications simultaneously. The maximal regimen durability with regard to safety and efficacy is a critical factor for long-term success of ART since modification to cART has a number of challenges.

Objectives: To assess the rate, time to change, reasons and predictors of treatment modification among HIV/AIDS patients at Pawe General Hospital.

Method: Hospital based retrospective cohort study was conducted among adult HIV/AIDS patients on follow-up in Pawe Hospital from 01 April 2017 to 30 April 2017. Patients who started cART at Pawe General Hospital from January 2012 to December 2016 were included. Data abstraction tool was used to collect data from patient chart. Data were analyzed using SPSS version 21. Descriptive statistics were used to summarize patient socio-demographics characteristics and rate of regimen modification. Bivariate and multivariate Cox proportional hazard were performed to identify the predictors.

Result: Over a median follow-up period of 21 months (IQR 6 - 38), 62 (14.5\%) patients modified their initial regimens (incidence rate (IR); 7.66 per 100 person years [95\% Cl: $5.84-9.50]$ ). Toxicity was the most common reason (72.6\%). In multivariate Cox regression model, WHO stage III/IV at initiation(AHR;2.39, 95\% Cl: 1.23 - 4.66), AZT based initial NRTI backbone (AHR; 8.19, 95\% Cl: 4.55 - 14.73), low baseline hemoglobin ( $(<7 \mathrm{~g} / \mathrm{dl}$ [AHR; 6.32, 95\% Cl: 1.40 - 28.58] and 7-9.9 g/dl [AHR 4.21, 95\% Cl: 1.92 - 9.22]) and co-medication with cART (AHR 1.73, 95\% Cl: 1.03 - 2.89) were associated with increased risk of treatment modification.

Conclusion: Initial regimen modification rate was lower in this population than cohorts in resource-rich settings. Special attention should be given for patients who are at advanced disease stage, AZT based regimen, low baseline hemoglobin and taking additional medications other than cART.

\section{Background}

The treatment of human immunodeficiency virus (HIV) infection has been revolutionized by potent antiretroviral therapy. Use of these multidrug regimens has resulted in substantial reductions in progression to AIDS, opportunistic infections, hospitalizations, and deaths (1). Combination antiretroviral therapy (cART) is the principal approach for preventing immune deterioration. With rare exception, all HIV infected individuals with detectable viremia, regardless of their CD 4 cell count, should begin antiretroviral therapy as soon as possible after diagnosis to prevent disease progression, improve clinical outcomes, and limit transmission (2). Sustained viral suppression, restoration of immunologic function, reduction of HIV related morbidity and mortality, improvement of quality of life and prolong survival has become an integral part of the continuum of HIV care (3). 
Once cART is initiated, patients generally remain on medications indefinitely. However, antiretroviral regimens commonly require changes which often involve switches of multiple medications simultaneously. This is often necessary because of the risk of acute toxicity, long-term toxicity, treatment failure, poor adherence, a desire for pregnancy, comorbidity with other chronic diseases or stock out of drugs (4). The approach depends on the reason for change, the amount of previous cART experience, and the available treatment options $(4,5)$. It becomes imperative to carefully select cART regimen at initiation and understand the determinants of regimen change in order to ensure treatment success (6).

A rate of treatment modification was 41.5 per 100 person year from the Swiss HIV Cohort Study 6.3 per 100 person years in a Swaziland Cohort and 13.8/100 person-year in Northern Thailand $(7,8,9)$. Moreover, $20 \%$ of patients in Southern India, $83 \%$ in Nigeria changed their first ART regimen $(10,11)$. In study conducted in University of Gondar Referral Hospital,Ethiopia rate of treatment modification was 10.11 per 100 person years (12). Predictors of switch to second-line regimen include older age, CD 4 count $\leq 100$ cells/mm3, drug toxicity, baseline WHO clinical stage III, occurrence of TB on the initial regimen, side effect on the initial regimen, co-medication with cART and baseline AIDS symptoms $(11,12,13)$.

Successive regimens are inferior to that of the original regimen in related to effectiveness and duration. In addition, regimen change result in a number of challenges; reduce both the duration and the chance of viral control due to cross resistance between different alternative drug and overlapping toxicity between and within a class of antiretroviral (ARV) drug. The likelihood that successful cART will last life time is poor and also second line cART is more expensive than that of first line cART. Patients failed on the first line drug are $46 \%$ more likely to fail again on the second line drug \& attributed to the higher number of side effects, have greater likelihood of experiencing drug resistance as a result of being on treatment longer $(14,15)$.

Therefore, it is important to devise ways to maximize the duration of patients on first line regimens in developing countries like Ethiopia, where resources are limited. But, there are limited data on the magnitude and predictors of cART regimen modification in Ethiopia especially in the study area, where there has been rapid scaling up of ART services over the past decade. In this study, the aim is to determine the magnitude and predictors of modification of first-line cART among HIV infected patients who initiated CART at the Pawe General Hospital. Findings from this study will have an input in understanding the magnitude and predictors of cART regimen change. This helps to work on the predictors and increase durability of cART regimen.

\section{Method And Participants}

\section{Study design and Study area}

Institutional based retrospective cohort study was conducted The study was conducted at ART clinic of Pawe General Hospital found in Benishangul Gumuz region, Ethiopia. Pawe Hospital is a general hospital which serves around four hundred thousand people of the Metekel zone and people from the neighboring 
zones of Amhara region. The HIV care service of the hospital was initiated in 2005 G.C and has 3 outpatient rooms, one voluntary testing and counseling room, one pharmacy, and one laboratory. Currently there are around 875 patients on cART medication in the hospital.The study was conducted from 1st April to 30, 2017 by reviewing the medical record of patients who started cART from January 2012 to December 2016.

\section{Inclusion Criteria}

All patients aged 15 and above who were started cART at Pawe General Hospital from 1st January 2012 to 31 st December 2016 and have at least one follow up visit were included in the study.

\section{Sample Size and sampling technique}

The minimum sample size required was calculated using EPI INFO Stat Calc program with the assumption of $95 \%$ level of confidence, $5 \%$ of marginal error and $80 \%$ power. From a previous study in Gondar referral hospital patients with WHO stage III at initiation of CART are at increased risk of initial regimen change by 1.92 times when compared to those who were stage I/II (26). Therefore, by using a power of 0.8 a minimum sample size of 342 to detect a minimum hazard ratio of 1.92 of initial regimen change between patients with WHO stage III vs WHO stage I/II was required. But in order to increase the power of this study all eligible patients who had started cART from January 2012 to December 2016 were taken as a sample and the charts of all patients with in this study period were reviewed.

\section{Data collection tool}

Data abstraction tool was developed by refering different articles done previously and was modified to match with ART follow up record of the setting. It includes; socio-demographic characteristics, clinical and immunologic characteristics, laboratory investigations and drug regimen modifications. The data was collected by two BSc nurses and two pharmacists who had ART training. The charts of the patient were identified using their patient identification number.

\section{Data Processing, Analysis and Presentation}

The data were entered to Epi data version 4.2 and exported to SPSS version 21. Then, it was cleaned for inconsistencies and missing values. Descriptive statistics were used to summarize socio-demographic and clinical data as well as rate of treatment modification. The survival analysis was carried out, as this study had considered time-to-event data, Cox proportional hazard model was fitted, and cumulative probabilities of regimen modification was estimated. The Kaplan-Meier curve and Log rank test were used to compare survival experiences between the different categories of the explanatory variables. Bivariate and multivariate Cox proportional hazard model was used to identify the predictors. Variables with $p$ value $<0.25$ in the bivariate analysis were entered into the multivariate proportional hazard model. The $95 \% \mathrm{Cl}$ of hazard ratio was computed and variable having $\mathrm{p}$ value $<0.05$ in the multivariate Cox proportional hazards model were considered as significantly and independently associated with the dependent variable. 


\section{Data Quality Management}

The data collectors were trained by the principal investigator before the data collection to have common understanding of the objectives of the study and data abstrction tool. The data abstraction tool was pretested on $5 \%$ of the sample size at the same facility to check for appropriateness and consistency and the necessary modification was made Frequent checks on the data collection process were made to ensure the completeness and consistency of the collected data. Quality of data was maintained by recruiting data collectors who had taken ART training. The retrieval process was closely monitored by supervisor throughout the data collection period. Completed questionnaires were checked regularly for completeness of information and any gaps identified were immediately communicated to the data collectors.

\section{Ethical Consideration}

Before starting the study, ethical clearance was obtained from the Institutional Review Board (IRB) of Jimma University. In addition, permission letter was obtained from the clinical director of the Pawe Hospital to conduct the study. The confidentiality of the patientswas maintained by avoiding name and identification number from data extraction tool and only numerical identifications were used as a reference.

\section{- Operational definitions}

\section{Treatment modification}

was defined as any change of one or more combination antiretroviral treatment components excluding dosage adjustment.

\section{Initial regimen modification}

a switch or substitution of at least one drug from the first cART regimen.

\section{Drug switch}

defined as a change from the first-line NNRTI-based to the second-line PI-based ARV regimen.

\section{Drug substitution}

defined as the replacement of one or more drugs in the first-line regimen (NRTI or NNRTI) with another drug from the same class (NRTI or NNRTI). Change between 3TC and FTC (or vice versa) is not classified as a drug substitution because these are considered therapeutically interchangeable.

\section{Discontinuation}

was defined as stopping any antiretroviral drug for at least 4 weeks. 


\section{Censoring}

Patients with the first date of lost to follow up, transfer out, death before the end of the follow up period and completed the follow up period without developed the event were considered as censored in this study.

\section{Co-medication}

medication taken with cART other than $\mathrm{CPT}$, INH, fluconazole prophylaxis.

Adherence:

Good

those patients with adherence level with $95 \%$ and above.

Fair

patients with having adherence level of $85 \%-95 \%$.

Poor

those patients having adherence level of less than $85 \%$.

\section{Results}

\section{Baseline Characteristics of Study Participants}

A total of 428 participants aged 15 years and above who initiated treatment were enrolled in this study and their records were analyzed. The mean age at the initiation of cART was $31.8 \pm 8.8$ years and 194 (45.3\%) of the participant were in the age group between 25 and 34 years. More than half of the respondents 250 (58.4\%) were female and majority 357 (83.4\%) of them were Orthodox Christian. Regarding the level of education, 125 (29.2\%) of the respondents have completed primary education. More than half $232(54.2 \%)$ of the respondents were married. Nearly half $206(48.1 \%)$ of the respondents were urban dwellers. A total of 345 (80.6\%) patients had disclosed their HIV status to either their family member or other relatives (Table 1).

Table 1:Baseline socio demographic characteristics of HIV positive adults at initiation of CART at Pawe General Hospital, January 2012 to December 2016( $(n=428)$ 


\begin{tabular}{|c|c|c|c|}
\hline Variable & Category & Frequency & Percentage (\%) \\
\hline \multirow[t]{2}{*}{ Gender } & Male & 178 & 41.6 \\
\hline & Female & 250 & 58.4 \\
\hline \multirow[t]{5}{*}{ Age (in years) } & $15-24$ & 75 & 17.5 \\
\hline & $25-34$ & 194 & 45.3 \\
\hline & $35-44$ & 114 & 26.6 \\
\hline & $45-54$ & 36 & 8.4 \\
\hline & $\geq 55$ & 9 & 2.1 \\
\hline \multirow[t]{5}{*}{ Marital status } & Married & 232 & 54.2 \\
\hline & Divorced & 78 & 18.2 \\
\hline & Single & 62 & 14.5 \\
\hline & Separated & 31 & 7.2 \\
\hline & Widowed & 25 & 5.8 \\
\hline \multirow[t]{4}{*}{ Educational status } & No formal education & 205 & 47.9 \\
\hline & Primary & 126 & 29.4 \\
\hline & Secondary & 70 & 16.4 \\
\hline & Tertiary & 27 & 6.3 \\
\hline \multirow[t]{6}{*}{ Occupation } & Farmer & 122 & 28.5 \\
\hline & House wife & 85 & 19.9 \\
\hline & Daily laborer & 78 & 18.2 \\
\hline & Government employer & 74 & 17.3 \\
\hline & Merchant & 51 & 11.9 \\
\hline & Others & 18 & 4.2 \\
\hline \multirow[t]{4}{*}{ Religion } & Orthodox & 358 & 83.6 \\
\hline & Muslim & 46 & 10.7 \\
\hline & Catholic & 15 & 3.5 \\
\hline & Protestant & 9 & 2.1 \\
\hline \multirow[t]{2}{*}{ Residence } & Urban & 206 & 48.1 \\
\hline & Rural & 222 & 51.9 \\
\hline
\end{tabular}




\begin{tabular}{|llll|} 
Disclosure status & Disclosed & 345 & 80.6 \\
\cline { 2 - 4 } & Not Disclosed & 83 & 19.4 \\
\hline
\end{tabular}

\section{Baseline clinical and immunological status of the respondents}

Nearly half $213(49.8 \%)$ of the study subjects were WHO clinical stage III at the initiation of the cART. Around 145 (33.9\%) of the participants had CD4 count of 200-349 cells/mm3. The median CD4 count at initiation of cART was 243 (IQR 128.25 - 359.75) cells/ mm3. The mean weight of the Participant was $50.86 \pm 9.20 \mathrm{~kg}$. Majority $348(81.3 \%)$ of the participants were adherent to their medication and 347 $(81.1 \%)$ of them were on working functional status at a baseline. The predominant cART regimen initially prescribed for them were a combination of Tenofovir, Lamivudine and Efavirenz (TDF-3TC-EFV), 290 (67.8\%) followed by Zidovudine, Lamivudine and Nevirapine (AZT-3TC-NVP) for $72(16.8 \%)$ cases. One hundred sixty-nine $(39.5 \%)$ of the study participants were diagnosed for opportunistic infection before initiation of CART and after confirmation of HIV infection. Majority $332(77.6 \%)$ of participants were started TDF as an initial NRTI backbone and 314 (73.4 \%) of them were initiated on EFV based regimen. Fifty-six patients (13.1\%)also had tuberculosis and taking anti-TB medications with cART.Around 341 $(80 \%)$ of the patients were taking the CPT prophylaxis and $235(54.9 \%)$ were taking INH prophylaxis. A total $167(39 \%)$ of the patients were also taking medications other than CPT, INH and fluconazole prophylaxis on top of cART medications. Nearly half, $219(51.2 \%)$ of study subjects were started cART at hemoglobin level of $10-12.9 \mathrm{~g} / \mathrm{dl}$ (Table 2).

Table 2: Baseline clinical and immunological status of HIV positive adults at initiation of CART, Pawe General Hospital, January 2012 to December $2016(n=428)$ 


\begin{tabular}{|c|c|c|c|}
\hline Characteristics & Category & Frequency & Percentage (\%) \\
\hline \multirow[t]{4}{*}{ WHO clinical stage } & stage I & 87 & 20.3 \\
\hline & stage II & 102 & 23.8 \\
\hline & stage III & 213 & 49.8 \\
\hline & stage IV & 26 & 6.1 \\
\hline \multirow[t]{4}{*}{ Baseline CD4 count } & $<100$ cells $/ \mathrm{mm} 3$ & 79 & 18.5 \\
\hline & 100-199 cells $/ \mathrm{mm} 3$ & 91 & 21.3 \\
\hline & $200-349$ cells $/ \mathrm{mm} 3$ & 145 & 33.9 \\
\hline & $\geq 350$ cells $/ \mathrm{mm} 3$ & 113 & 26.4 \\
\hline \multirow[t]{3}{*}{ Adherence } & Good & 348 & 81.3 \\
\hline & Fair & 19 & 4.4 \\
\hline & Poor & 61 & 14.3 \\
\hline \multirow[t]{3}{*}{ Functional status } & Working & 347 & 81.1 \\
\hline & Ambulatory & 69 & 16.1 \\
\hline & bed ridden & 12 & 2.8 \\
\hline \multirow[t]{2}{*}{ Baseline weight } & $<50 \mathrm{~kg}$ & 185 & 43.2 \\
\hline & $\geq 50 \mathrm{~kg}$ & 243 & 56.8 \\
\hline \multirow[t]{4}{*}{ Initial cART regimen } & AZT/3TC/NVP & 72 & 16.8 \\
\hline & AZT/3TC/EFV & 24 & 5.6 \\
\hline & TDF/3TC/EFV & 290 & 67.8 \\
\hline & TDF/3TC/NVP & 42 & 9.8 \\
\hline \multirow[t]{2}{*}{ Past OI before initiation of cART } & Yes & 169 & 39.5 \\
\hline & No & 259 & 60.5 \\
\hline \multirow[t]{2}{*}{ Tuberculosis } & Yes & 56 & 13.1 \\
\hline & No & 372 & 86.9 \\
\hline \multirow[t]{2}{*}{ Initial NRTI backbone } & AZT & 96 & 22.4 \\
\hline & TDF & 332 & 77.6 \\
\hline \multirow[t]{2}{*}{ Initial NNRTI } & NVP & 114 & 26.6 \\
\hline & EFV & 314 & 73.4 \\
\hline
\end{tabular}




\begin{tabular}{|llll|}
\hline CPT prophylaxis & Yes & 341 & 79.7 \\
\cline { 2 - 3 } INH prophylaxis & No & 87 & 20.3 \\
\hline \multirow{2}{*}{ Fluconazole prophylaxis } & Yes & 235 & 54.9 \\
\cline { 2 - 3 } & No & 193 & 45.1 \\
\hline Co-medication & Yes & 13 & 3.0 \\
\cline { 2 - 4 } & No & 415 & 97.0 \\
\hline Baseline Hemoglobin & No & 167 & 39.0 \\
& $<7 \mathrm{~g} / \mathrm{dl}$ & 261 & 61.0 \\
\cline { 2 - 4 } & $7-9.9 \mathrm{~g} / \mathrm{dl}$ & 8 & 1.9 \\
\cline { 2 - 4 } & $10-12.9 \mathrm{~g} / \mathrm{dl}$ & 219 & 15.7 \\
& $\geq 13 \mathrm{~g} / \mathrm{dl}$ & 142 & 33.2 \\
\hline
\end{tabular}

\section{Rate of Regimen Modification}

Four hundred twenty-eight study subjects who were followed for different period gave a total of 9709.47 person months (809.12 person years (PY)) of observation. Within this follow up period, modification of initial regimen were made for a total of $62(14.5 \%)$ patients. This makes the overall rate of initial regimen modification 7.66/100 PY (95\% Cl 5.84 - 9.50). Regarding time to initial regimen modification, 32 (51.6\%), $38(61.3 \%)$ and 57 (91.9\%) changed their regimen within 6 months, 1 year and 3 years respectively. The remaining $5(8.1 \%)$ changed after 3 years of follow up.The cumulative probability of surviving on initial regimen at the end of 6 months was 0.92; at the end of one years was 0.90; at the end of 3 years was 0.82 and at the end of follow-up was 0.76 (Figure 1). The most common reason for regimen modification was toxicity/side effect which accounts about $45(72.6 \%)$ of the cases and contribute for 5.56/100 PY (95\% Cl 3.98 - 7.14). Treatment failure $13(21.0 \%)$ and TB $4(6.5 \%)$ were the other reasons for the regimen modification. (Table 3 ).

Table 3: Reasons for regimen modification and common toxicity/side effects among patients with initial regimen modification at Pawe General Hospital, January 2012 to December $2016(n=62)$ 


\begin{tabular}{|c|c|c|c|c|}
\hline Characteristics & & Frequency & $\begin{array}{l}\text { Percentage } \\
(\%)\end{array}$ & $\begin{array}{l}\text { Incidence rate }[95 \% \\
\mathrm{Cl}]\end{array}$ \\
\hline \multirow[t]{3}{*}{ Reason for modification } & Toxicity & 45 & 72.6 & $\begin{array}{l}5.56 / 100 \mathrm{PY}[3.98- \\
7.14]\end{array}$ \\
\hline & $\begin{array}{l}\text { Treatment } \\
\text { failure }\end{array}$ & 13 & 21.0 & $\begin{array}{l}1.60 / 100 P Y[0.73- \\
2.46]\end{array}$ \\
\hline & Tuberculosis & 4 & 6.5 & $\begin{array}{l}0.50 / 100 P Y[0.01- \\
0.97]\end{array}$ \\
\hline \multirow[t]{4}{*}{$\begin{array}{l}\text { Type of toxicity/ Side } \\
\text { effect }\end{array}$} & Anemia & 23 & 51.1 & $\begin{array}{l}2.84 / 100 P Y[1.69- \\
3.98]\end{array}$ \\
\hline & Rash & 13 & 28.9 & $\begin{array}{l}1.60 / 100 P Y[0.73- \\
2.46]\end{array}$ \\
\hline & CNS toxicity* & 7 & 15.5 & $\begin{array}{l}0.87 / 100 P Y[0.23- \\
1.50]\end{array}$ \\
\hline & Renal failure & 2 & 4.4 & $\begin{array}{l}0.25 / 100 P Y[0.09- \\
0.59]\end{array}$ \\
\hline
\end{tabular}

\section{Predictor of regimen modification}

From the covariates included in the model baseline WHO clinical stage, baseline hemoglobin, comedication with cART, residence, disclosure status, initial NRTI backbone, initial NNRTI, occurrence of TB, and fluconazole prophylaxis were significantly associated with outcome variable at p-value 0.25 in bivariate analysis. Those variables which have $p$-value less than 0.25 in the bivariate analysis were included in the multivariate model for analysis. In the multivariate Cox-regression analysis, baseline WHO clinical stage, co-medication with cART, initial NRTI backbone, and baseline hemoglobin of the patient remained a significant predictors of the initial regimen modification. Baseline WHO clinical stage III/IV at CART initiation (AHR 2.39, 95\% Cl: 1.23 - 4.66), and individuals who initiated cART with AZT as an initial NRTI backbone (AHR 8.19, 95\% Cl: 4.55 - 14.73) were more likely to experience an initial treatment modification of their CART regimen. There was no statistical association between the use of nevirapinecontaining regimens as initial CART regimen and treatment modification. The increased risk of regimen modification among patients taking medications other than CPT, INH and fluconazole prophylaxis with CART were 1.73 times compared with those who did not take other medications (AHR 1.73, 95\% Cl:1.03 2.89). Patients having low baseline hemoglobin ( $<7 \mathrm{~g} / \mathrm{dl}$ [AHR $6.32,95 \% \mathrm{Cl}: 1.40-28.58$ ] and 7-9.9 g/dl [AHR 4.21, 95\% Cl: 1.92 - 9.22]) were at higher risk for regimen modification compared with those patients with high baseline hemoglobin. (Table4).

Table 4: Bivariate and multivariable Cox regression analysis for predictors of initial cART regimen modification among adult HIV positive patients at Pawe General Hospital, January 2012 to December, $2016(n=428)$ 


\begin{tabular}{|c|c|c|c|c|c|c|c|}
\hline \multirow[t]{2}{*}{ Variable } & & \multicolumn{2}{|c|}{$\begin{array}{l}\text { Regimen } \\
\text { Modification }\end{array}$} & \multirow[t]{2}{*}{$\begin{array}{l}\text { Crude HR } \\
\text { (95\% Cl) }\end{array}$} & \multirow[t]{2}{*}{$\begin{array}{l}P- \\
\text { value }\end{array}$} & \multirow{2}{*}{$\begin{array}{l}\text { Adjusted } \\
\mathrm{HR}(95 \% \\
\mathrm{Cl})\end{array}$} & \multirow[t]{2}{*}{$\begin{array}{l}\mathrm{P} \text { - } \\
\text { value }\end{array}$} \\
\hline & & Yes & No & & & & \\
\hline \multirow[t]{2}{*}{ Gender } & Female & 36 & 214 & 1 & & & \\
\hline & Male & 26 & 152 & $\begin{array}{l}1.120 \\
{[0.676,1.856]}\end{array}$ & 0.659 & & \\
\hline \multirow[t]{2}{*}{ Age (years) } & $<30$ & 30 & 156 & 1 & & & \\
\hline & $\geq 30$ & 32 & 210 & $\begin{array}{l}0.843 \\
{[0.512,1.387]}\end{array}$ & 0.502 & & \\
\hline \multirow[t]{2}{*}{ Marital status } & Married & 36 & 196 & 1 & & & \\
\hline & Unmarried & 26 & 170 & $\begin{array}{l}1.240 \\
{[0.615,2.500]}\end{array}$ & 0.548 & & \\
\hline \multirow[t]{4}{*}{$\begin{array}{l}\text { Educational } \\
\text { status }\end{array}$} & $\begin{array}{l}\text { No formal } \\
\text { education }\end{array}$ & 30 & 175 & $\begin{array}{l}0.663 \\
{[0.276,1.593]}\end{array}$ & 0.358 & & \\
\hline & Primary & 16 & 110 & $\begin{array}{l}0.525[0.203 \\
1.354]\end{array}$ & 0.183 & & \\
\hline & Secondary & 10 & 60 & $\begin{array}{l}0.805[0.298 \\
2.180]\end{array}$ & 0.670 & & \\
\hline & Tertiary & 6 & 21 & 1 & & & \\
\hline \multirow[t]{6}{*}{ Occupation } & Farmer & 13 & 109 & 1 & & & \\
\hline & House wife & 13 & 72 & $\begin{array}{l}1.284[0.595 \\
2.771]\end{array}$ & 0.524 & & \\
\hline & Daily laborer & 10 & 68 & $\begin{array}{l}1.027[0.449 \\
2.348]\end{array}$ & 0.951 & & \\
\hline & $\begin{array}{l}\text { Government } \\
\text { employed }\end{array}$ & 15 & 59 & $\begin{array}{l}1.756[0.835 \\
3.691]\end{array}$ & 0.137 & & \\
\hline & Merchant & 9 & 42 & $\begin{array}{l}1.673[0.715 \\
3.917]\end{array}$ & 0.235 & & \\
\hline & Others* & 2 & 16 & $\begin{array}{l}1.014[0.229 \\
4.497]\end{array}$ & 0.985 & & \\
\hline \multirow[t]{2}{*}{ Residence } & Rural & 22 & 200 & 1 & & & \\
\hline & Urban & 40 & 166 & $\begin{array}{l}1.759[1.045, \\
2.960]\end{array}$ & 0.034 & & \\
\hline \multirow[t]{2}{*}{ Adherence } & Good & 47 & 301 & 1 & & & \\
\hline & Fair & 4 & 15 & $\begin{array}{l}2.491[0.895 \\
6.931]\end{array}$ & 0.080 & & \\
\hline
\end{tabular}




\begin{tabular}{|c|c|c|c|c|c|c|c|}
\hline & Poor & 11 & 50 & $\begin{array}{l}1.455[0.755 \\
2.807]\end{array}$ & 0.263 & & \\
\hline \multirow{2}{*}{$\begin{array}{l}\text { Disclosure } \\
\text { status }\end{array}$} & Disclosed & 42 & 303 & 1 & & & \\
\hline & Not disclosed & 20 & 63 & $\begin{array}{l}1.925 \text { [1.129, } \\
3.280]\end{array}$ & 0.016 & & \\
\hline \multirow{2}{*}{$\begin{array}{l}\text { Baseline WHO } \\
\text { clinical stage }\end{array}$} & Stage I/II & 11 & 178 & 1 & & 1 & \\
\hline & Stage III/IV & 51 & 188 & $\begin{array}{l}3.948[2.057, \\
7.577]\end{array}$ & 0.000 & $\begin{array}{l}2.393 \\
\text { [1.228, } \\
4.663]\end{array}$ & 0.010 \\
\hline \multirow[t]{2}{*}{ Past OI } & Yes & 27 & 142 & $\begin{array}{l}1.063 \text { [0.643, } \\
1.759]\end{array}$ & 0.810 & & \\
\hline & No & 35 & 224 & 1 & & & \\
\hline \multirow{3}{*}{$\begin{array}{l}\text { Functional } \\
\text { status }\end{array}$} & Working & 49 & 298 & 1 & & & \\
\hline & Ambulatory & 12 & 57 & $\begin{array}{l}1.421[0.755 \\
2.674]\end{array}$ & 0.276 & & \\
\hline & Bed ridden & 1 & 11 & $\begin{array}{l}1.239[0.171, \\
8.996]\end{array}$ & 0.832 & & \\
\hline \multirow[t]{2}{*}{ Tuberculosis } & Yes & 13 & 43 & $\begin{array}{l}2.036[1.103, \\
3.756]\end{array}$ & 0.023 & & \\
\hline & No & 49 & 323 & 1 & & & \\
\hline \multirow[t]{2}{*}{$\begin{array}{l}\text { Initial NRTI } \\
\text { backbone }\end{array}$} & AZT & 40 & 56 & $\begin{array}{l}6.550 \text { [3.885, } \\
11.044]\end{array}$ & 0.000 & $\begin{array}{l}8.188 \\
{[4.551,} \\
14.732]\end{array}$ & 0.000 \\
\hline & TDF & 22 & 310 & 1 & & 1 & \\
\hline \multirow[t]{2}{*}{ Initial NNRTI } & NVP & 36 & 78 & $\begin{array}{l}3.503[2.101, \\
5.840]\end{array}$ & 0.000 & & \\
\hline & EFV & 26 & 288 & 1 & & & \\
\hline \multirow[t]{2}{*}{ CPT prophylaxis } & Yes & 57 & 284 & $\begin{array}{l}2.405 \text { [0.961, } \\
6.017]\end{array}$ & 0.061 & & \\
\hline & No & 5 & 82 & 1 & & & \\
\hline \multirow[t]{2}{*}{ INH prophylaxis } & Yes & 27 & 208 & $\begin{array}{l}0.634[0.383 \\
1.050]\end{array}$ & 0.076 & & \\
\hline & No & 35 & 158 & 1 & & & \\
\hline \multirow[t]{2}{*}{ Fluconazole } & Yes & 5 & 8 & $\begin{array}{l}\text { 3.343 [1.336, } \\
8.369]\end{array}$ & 0.010 & & \\
\hline & No & 57 & 358 & 1 & & & \\
\hline Co-medication & Yes & 37 & 131 & 2.260 [1.360, & 0.002 & 1.728 & 0.037 \\
\hline
\end{tabular}




\begin{tabular}{|c|c|c|c|c|c|c|c|}
\hline & & & \multicolumn{3}{|c|}{$3.755]$} & \multicolumn{2}{|l|}{$\begin{array}{l}{[1.034,} \\
2.889]\end{array}$} \\
\hline & No & 25 & 235 & 1 & & 1 & \\
\hline \multirow[t]{2}{*}{ CD4 count } & $\begin{array}{l}<200 \\
\text { cell } / \mathrm{mm} 3\end{array}$ & 27 & 143 & $\begin{array}{l}1.105[0.669 \\
1.826]\end{array}$ & 0.696 & & \\
\hline & $\begin{array}{l}\geq 200 \\
\text { cell } / \mathrm{mm} 3\end{array}$ & 35 & 223 & 1 & & & \\
\hline \multirow[t]{2}{*}{ Baseline weight } & $<50 \mathrm{~kg}$ & 27 & 158 & 1 & & & \\
\hline & $\geq 50 \mathrm{~kg}$ & 35 & 208 & $\begin{array}{l}1.001[0.605 \\
1.655]\end{array}$ & 0.391 & & \\
\hline \multirow[t]{4}{*}{ Baseline Hgb } & $<7 \mathrm{~g} / \mathrm{gl}$ & 2 & 6 & $\begin{array}{l}3.397[0.782, \\
14.754]\end{array}$ & 0.013 & $\begin{array}{l}6.319 \\
{[1.397} \\
28.585\end{array}$ & 0.017 \\
\hline & $7-9.9 \mathrm{~g} / \mathrm{dl}$ & 14 & 45 & $\begin{array}{l}2.279[1.123 \\
4.626]\end{array}$ & 0.023 & $\begin{array}{l}4.212 \\
\text { [1.924, } \\
9.221]\end{array}$ & 0.000 \\
\hline & $10-12.9 \mathrm{~g} / \mathrm{dl}$ & 29 & 190 & $\begin{array}{l}1.071[0.589, \\
1.950]\end{array}$ & 0.822 & & \\
\hline & $\geq 13 \mathrm{~g} / \mathrm{dl}$ & 17 & 125 & 1 & & 1 & \\
\hline
\end{tabular}

*drivers, soldiers, custodians;

\section{Discussions}

Since the choices of regimen are still limited in most of low- and middle-income countries, well-managed first line CART is essential. Repeated investigation of the incidence of regimen modification and its determinants will help to keep patients on the first cART regimen as long as possible. Over the median follow-up time of 21 months (IQR 6-38), 62 (14.5\%) of the patients in this cohort modified their initial antiretroviral regimen. This result is nearly in line with study conducted in Swaziland (7) but the proportion is somewhat lower than that reported from previous studies (10) and also studies in Ethiopia $(12,16)$. The probable reason for this may be explained as the previous studies had included stavudine in their first line regimen which may be the most common contributor for regimen modification due to drug toxicity but this study excluded stavudine due to its phase out during the study period.

The rate of initial regimen change among adult HIV patients on CART was found to be $7.66 / 100 \mathrm{PY}$ (95\% $\mathrm{Cl} 5.84,9.50 \mathrm{PY}$ ). This finding is lower than a study conducted in Swiss 41.5/100PY (8), Brazil 28.3/100PY (17), multicenter study in North America and Europe 14.4/100PY (18)and Thailand $13.8 / 100 \mathrm{PY}$ (9). This might be explained by the difference in defining outcome variables, since in this study treatment discontinuation was not considered as regimen modification unless they restart with 
different regimen. Furthermore, limited combined antiretroviral options in our setting may limit the clinician decision on CART modification due to treatment failure. The other possible reasons might be regular monitoring of viral load for treatment response in developed countries might pick virological failure earlier which calls the need for regimen change.

Similarly, it is lower than studies done in Kenya and West Africa with a rate of 18.6/100PY and $16.2 / 100 P Y$ respectively $(13,19)$. This might be due to the difference in follow up period 10.7 and 15 months in Kenyan and West Africa study but 21 months for our study. In addition to this, our study included participants who started CART after 2012 in which WHO recommended to phase out D4T but Kenyan and West Africa studies were done before 2011 which might overestimate the rate.

The main reason for regimen modification was toxicity which accounts about 45 (72.6\%) of the cases and contribute for 5.56/100 PY (95\% Cl 3.98-7.14) followed by treatment failure $13(21.0 \%)$ and tuberculosis 4 (6.5\%). The common types of toxicities were anemia $23(51.1 \%)$, rash $13(28.9 \%)$, CNS toxicity $7(15.5 \%)$, and renal failure $2(4.4 \%)$. This is also similar with other studies (20)done in Mekelle $(12,16,21)$ and Gondar(12).

In this study the baseline WHO clinical stage III/IV at initiation, co-medication with cART, AZT based initial NRTI backbone, and baseline hemoglobin of the patient was found to be predictors for initial regimen modification.

Those patients who were WHO clinical stage III/IV at the initiation of CART were 2.39 times at higher risk of changing their initial regimen as compared to those with WHO clinical stage $\mathrm{I} / \mathrm{II}$. This finding is also supported with studies done in Swaziland (7) and two Kenyan studies $(13,20)$ and study done in Gondar (12). This might be due to the fact that those patients who had advanced disease are likely to be on other medications which might result in drug interaction, side effect which in turns result in regimen modification.

Regarding the initial NRTI backbone, patients initiated with AZT based CART regimen had 8.19 times greater chance of changing their initial cART regimen compared to those initiated with TDF based CART regimen. AZT based regimen was the dominant regimen to cause initial CART regimen modification due to its hematological toxicity and this finding was harmonized with a number of different studies $(22,23)$. This result is also in agreement with study done in Mekelle (16). This might be justified possibly with those patients initiated with AZT based regimen were at the higher risk for developing hematological adverse effects and may result in regimen modification when compared with TDF based regimen as initial NRTI backbone.

Patients who were taking other concurrent medications with cART treatment were 1.73 times at a greater risk of changing their initial regimen at any time as compared to those who did not take other medication. This result shows that not to use additional drugs up on the CART regimen have a protective effect for treatment regimen modification. This study is also in line with Swiss HIV Cohort Study (8) and studies conducted in Ethiopia at Mekelle hospital (16) and Gondar Referral hospital (12). The possible reason for 
this may the need of co-medication particularly for comorbidities in patients with advanced disease and concomitant treatment of opportunistic infections, may cause drug-drug interactions, leading to an increase in transaminase levels and thus treatment modification as a result of drug-drug interactions and cumulative drug toxicity which may finally leads to regimen modification. The other possible explanation might be poly pharmacy which could lead to poor adherence due to pill burden which in turn resulted in poor efficacy of treatment result in regimen modification secondary to treatment failure.

Patients having the low level of hemoglobin during the initiation of cART are at the increased risk for the modification of the regimen. Those patients with hemoglobin $<7 \mathrm{~g} / \mathrm{dl}$ were 6.32 times and those having between 7-9.9 g/dl were 4.21 times at increased risk of initial regimen modification. Even though this is not a significant predictor from previous studies, the reason might be explained as those patients with lower hemoglobin level were at higher risk of developing anemia which is one of the common reason for the treatment modification.

\section{Conclusion}

Initial regimen modification rate was found to be lower in this population than in cohorts in resourcesettings and nearly half of the modification was occurred within the first six months of the initiation of CART. Being WHO stage III/IV at initiation, AZT based initial NRTI backbone; low baseline hemoglobin and co-medication with CART were found to be predictors of regimen modification. Therefore, special attention should be given for patients who are at advanced disease stage, AZT based regimen and taking additional medications other than CART. Toxicity was the most common reason for antiretroviral regimen modification as AZT was the most substituted drug with anemia being the most common side effect.

\section{Abbreviations}

AIDS

acquired immunodeficiency syndrome, ARV = antiretroviral, AZT = Zidovudine, $\mathrm{cART}=$ Combination antiretroviral therapy, $\mathrm{CD} 4=$ cluster of differentiation, $\mathrm{Cl}=$ confidence interval; $\mathrm{CNS}=$ central nervous system; CPT = Co-trimoxazole preventive therapy, EFV = Efavirenz, $\mathrm{Hgb}=$ hemoglobin, $\mathrm{HIV}=$ human immunodeficiency virus, $\mathrm{HR}$ = hazard ratio, $\mathrm{INH}=$ isoniazid, $\mathrm{NNRTI}$ = non-nucleoside reverse transcriptase inhibitors, NRTI = nucleoside reverse transcriptase inhibitors, NVP = Nevirapine, $\mathrm{OI}=$ opportunistic infection, $\mathrm{PY}=$ person-years, $3 \mathrm{TC}=$ Lamivudine, $\mathrm{TDF}=$ Tenofovir,

\section{Declarations}

\section{Ethics approval and consent to participate}

A letter of ethicalclearance was secured from institute review board of instiute of health, Jimma University (IHRPGC/105/207) before conucting the study. Informed consent was also obtained from the partcipants. 


\section{Consent for publication}

Not applicable

\section{Availability of data and materials}

The used for this study is avaiable upon request

\section{Competing interests}

The authors declare that they have no competing interests.

\section{Funding}

The study was funded by Jimma University. Jimma University has no any role in the design of the study and collection, analysis, and interpretation of data and in writing the manuscript.

\section{Authors' contributions}

TM conceived the idea, designed the method and wrote the proposal, participated in data collection process, interepreted data, analyze data and draft the paper. GM and HJ designed the method, participated in data analysis, interepreted data and reviewed the manuscript. All authors read and approved the final manuscript.

\section{Acknowledgements}

We would like to thank Pawe General Hospital ART clinic staff members for their kind cooperation. We would also like to extend our thanks to data collectors.

\section{Author details}

$1 \& 3^{\star}$ Jimma University, Institute of Health, Faculty of Health Sciences, School of Pharmacy, ${ }^{2}$ Jimma University, Institute of Health, Faculty of Public Health, Epidemiology department

\section{References}

1. Sterne JA, Hernán MA, Ledergerber B, Tilling K, Weber R, Sendi P, et al. Long-term effectiveness of potent antiretroviral therapy in preventing AIDS and death: a prospective cohort study. The lancet. 2005;366(9483):378-84.

2. Günthard HF, Saag MS, Benson CA, Del Rio C, Eron JJ, Gallant JE, et al. Antiretroviral drugs for treatment and prevention of HIV infection in adults: 2016 recommendations of the International Antiviral Society-USA panel. Jama. 2016;316(2):191-210.

3. Birhanu S, Bussa Z, Gebre M, Addisu N. Rationale for changing initial highly active antiretroviral therapy(HAART) regimen among HIV/AIDS patients in west Ethiopia,International Journal of Life 
Sciences and Review (IJLSR). 2015; 1(1): 13-19.

4. Jima YT, Angamo MT, Wabe NT. Causes for antiretroviral regimen change among HIV/AIDS patients in Addis Ababa, Ethiopia. Tanzania journal of health research. 2013;15(1).

5. Wilkin T, Glesby M, Gulick RM. Switching antiretroviral therapy: why, when and how. IAPAC Mon. 2006;12(7):220-9.

6. AIDS A-LCotIDtE. Antiretroviral therapy in resource-limited settings 1996 to 2006: patient characteristics, treatment regimens and monitoring in sub-Saharan Africa, Asia and Latin America. Tropical medicine \& international health: TM \& IH. 2008;13(7):870.

7. Zuma K, Okello V. Durability of first line antiretroviral therapy: reasons and predictive factors for modifications in a Swaziland cohort. J Antivir Antiretrovir. 2012;4(1): 014-020.

8. Elzi L, Marzolini C, Furrer H, Ledergerber B, Cavassini M, Hirschel B, et al. Treatment modification in HIV-infected individuals starting combination antiretroviral therapy between 2005 and 2008. Arch Intern Med. 2010;170(1):57-65.

9. Tsuchiya N, Pathipvanich P, Wichukchinda N, Rojanawiwat A, Auwanit W, Ariyoshi K, et al. Incidence and predictors of regimen-modification from first-line antiretroviral therapy in Thailand: a cohort study. BMC Infect Dis. 2014;14(1):565.

10. Kumarasamy N, Vallabhaneni S, Cecelia AJ, Yepthomi T, Balakrishnan P, Saghayam S, et al. Reasons for modification of generic highly active antiretroviral therapeutic regimens among patients in southern India. JAIDS Journal of Acquired Immune Deficiency Syndromes. 2006;41(1):53-8.

11. Abah IO, Darin KM, Ebonyi AO, Ugoagwu P, Ojeh VB, Nasir N, et al. Patterns and predictors of first-line antiretroviral therapy modification in HIV-1-infected adults in a large urban outpatient cohort in Nigeria. Journal of the International Association of Providers of AIDS Care (JIAPAC). 2015:2325957414565508.

12. Anlay DZ, Alemayehu ZA, Dachew BA. Rate of initial highly active anti-retroviral therapy regimen change and its predictors among adult HIV patients at University of Gondar Referral Hospital, Northwest Ethiopia: a retrospective follow up study. AIDS research therapy. 2016;13(1):10.

13. Inzaule S, Otieno J, Kalyango J, Nafisa L, Kabugo C, Nalusiba J, et al. Incidence and predictors of first line antiretroviral regimen modification in western Kenya. PloS one. 2014;9(4):e93106.

14. Orrell C, Harling G, Lawn SD, Kaplan R, McNally M, Bekker L-G, et al. Conservation of first-line antiretroviral treatment regimen where therapeutic options are limited. Antivir Ther. 2007;12(1):83.

15. Blanco J, Clotet B. Learning from drug changes in antiretroviral therapy. Aids. 2013;27(5):833-4.

16. Bayou T, Woldu M, Meskel GG, Mezgebe H. Factors determinant for change of initial antiretroviral treatment regimen among patients on ART follow-up clinic of Mekelle Hospital, Mekelle, Ethiopia. Int J Basic Clin Pharmacol. 2014 Feb;3(1):44-49

17. Cardoso SW, Grinsztejn B, Velasque L, Veloso VG, Luz PM, Friedman RK, et al. Incidence of modifying or discontinuing first HAART regimen and its determinants in a cohort of HIV-infected patients from Rio de Janeiro, Brazil. AIDS Res Hum Retroviruses. 2010;26(8):865-74. 
18. Abgrall S, Ingle SM, May MT, Costagliola D, Mercie P, Cavassini M, et al. Durability of first Art regimen and risk factors for modification, interruption or death in Hiv-positive patients starting Art in Europe and North America 2002-2009. AIDS (London, England). 2013;27(5):803-13.

19. Landier J, Akonde A, Pizzocolo C, Haidara I, Drabo M, Pizarro L, et al. Switch to second-line ART in West African routine care: incidence and reasons for switching. AIDS care. 2011;23(1):75-8.

20. Owuor ALG, Otieno C, Omonge E, Maritim M, Memiah P. Modifcation of antiretroviral therapy in a cohort study of HIV-infected patients attending an urban teaching Hospital in Kenya. Int J Virol AIDS. 2014;1(003).

21. Gebremedhin L, Birhane A. Reasons for anti-retroviral regimen changes in HIV/AIDS patients of Ayder Referral Hospital ART clinic, Mekelle, Ethiopia. Int J Pharma Sci Res. 2014;5(0975-9492):693-700.

22. Lima DGL, de Arruda ÉAG, de Lima AJA, Oliveira BE, de França Fonteles MM. Factors determining changes in initial antiretroviral therapy. Revista da Associação Médica Brasileira (English Edition). 2012;58(2):222-8.

23. Boulle A, Orrell C, Kaplan R, Van Cutsem G, McNally M, Hilderbrand K, et al. Substitutions due to antiretroviral toxicity or contraindication in the first 3 years of antiretroviral therapy in a large South African cohort. Antivir Ther. 2007;12:753-60.

\section{Figures}

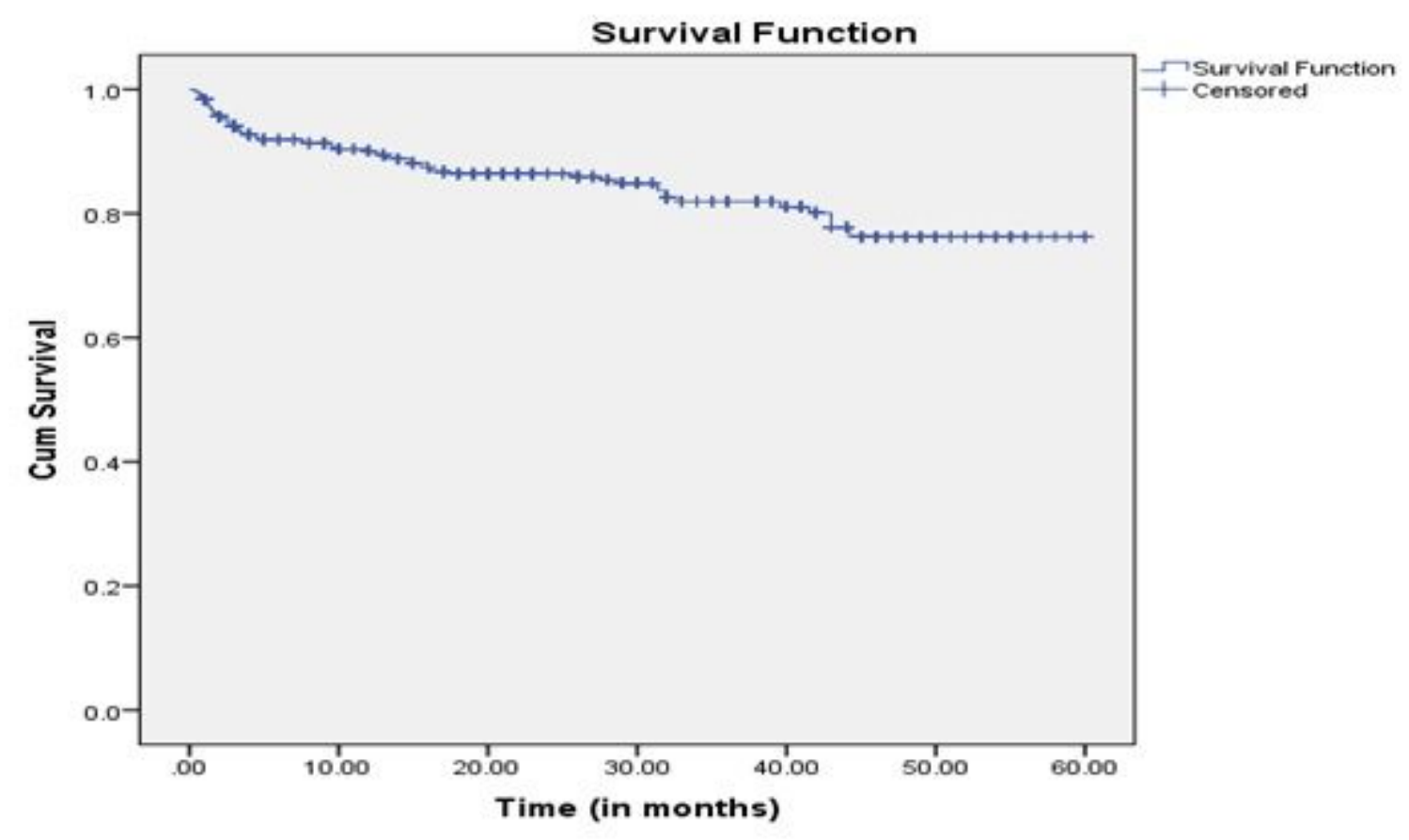

\section{Figure 1}

Kaplan-Meir curve of proportion surviving on initial regimen for adult HIV positive patients on initial cART at Pawe General hospital, starting from January 2012 to December 2016 


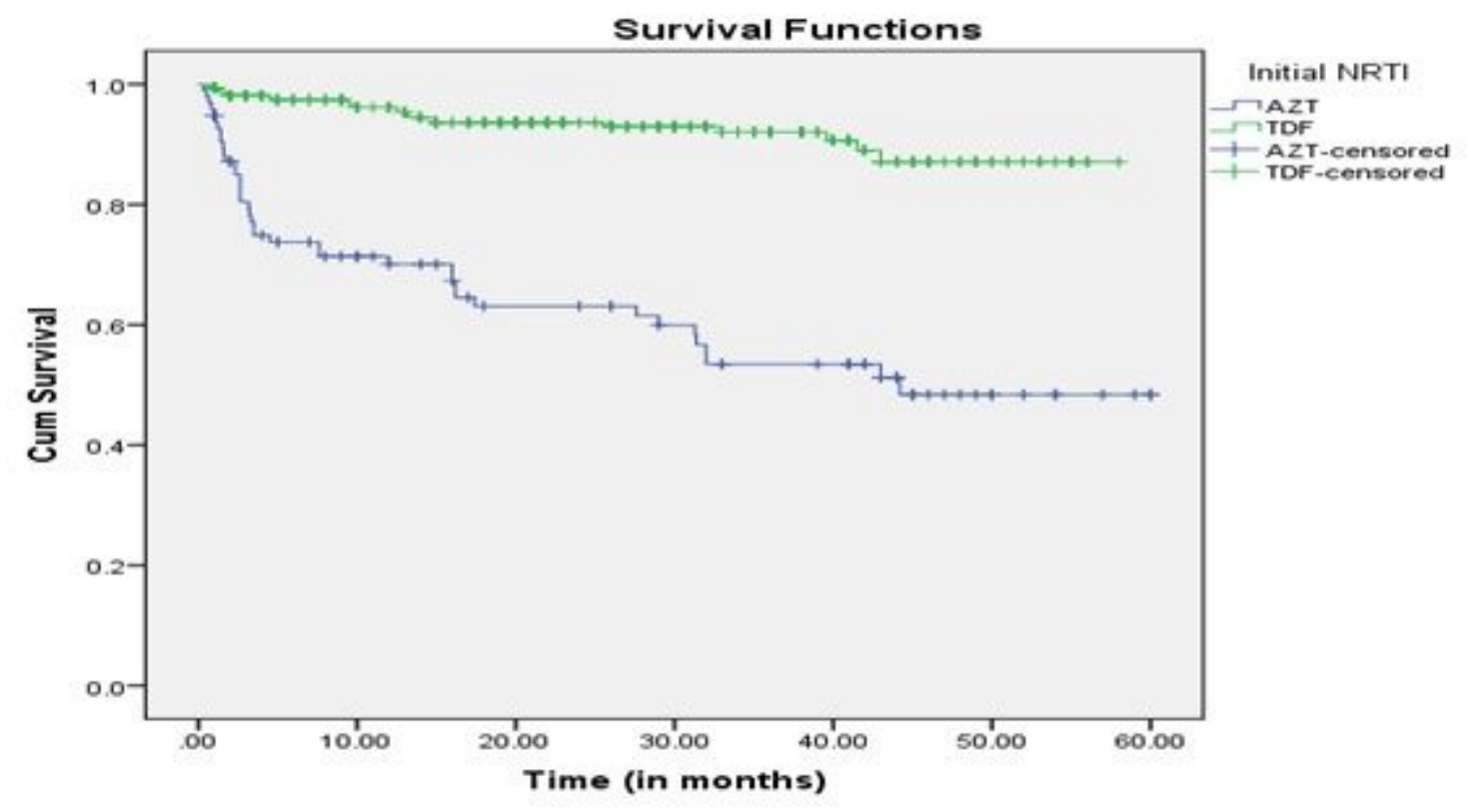

Figure 2

Kaplan-Meier curve of proportion surviving on initial regimen based on NRTI backbone at Pawe General hospital, starting from January 2012 to December 2016

\section{Supplementary Files}

This is a list of supplementary files associated with this preprint. Click to download.

- Additionaldocument1.docx 